\title{
Cephalic arteries in the European beaver Castor fiber
}

\author{
Hieronim FRACKOWIAK and Jan ŚMIEŁOWSKI
}

\begin{abstract}
Frąckowiak H. and Śmiełowski J. 1998. Cephalic arteries in the European beaver Castor fiber. Acta Theriologica 43: 219-224.

Cephalic arteries of 17 European beavers Castor fiber Linnaeus, 1758 were examined. After the common carotid arteries were injected with resin, the heads were biologically macerated. Differences between individual specimens as well as asymmetrical distribution of certain arteries were noted. It was found that in the European beaver the common carotid artery divided into external and internal carotid arteries. The internal carotid artery is well developed in C. fiber, whereas in some other rodents it may be obliterated. The examined beavers had no stapedial arteries.

Department of Animal Anatomy and Department of Zoology, Agricultural University of Poznań, Wojska Polskiego 71C, 60-625 Poznań, Poland (HF); Faculty of Animal Husbandry, Agriculture University of Poznań, Wojska Polskiego 28, 60-627 Poznań, Poland (JS)
\end{abstract}

Key words: Castor fiber, anatomy, cephalic arteries

\section{Introduction}

In the available literarure the descriptions of the arteries of the head in beavers (Castoridae) are infrequent. The cephalic arteries in the European beavers was generally described by Andreyeva (1954). Bugge (1971, 1974) described this arteries on the basis of two specimens. Also Guthrie (1963) desribed the arteries of the head in only one Canadian beaver Castor canadensis.

\section{Material and metods}

Studies were conducted on 17 specimens of the European beaver Castor fiber Linnaeus, 1758 of both sexes (10 males and 7 females). Three beavers were 12 month old, while the remaining animals were adult. Vascular casts of the cranial arteries were made by injecting polyester resins into both common carotid arteries (Munkacsi 1957). The preparations were macerated biologically. The circulus arteriosus with contributing branches were visualzed in 8 preparation. Arteries of all beavers were analyzed to calculate variation in the frequency of terminal vessels of the cephalic arterial system. 
Terminology used in the paper is in accordance with Nomina Anatomica Veterinaria (1983), and with that of Simoens et al. (1978-1979).

\section{Results}

The cephalic arterial system of the European beaver takes origin mainly from the common carotid arteries which further divide into external and internal carotid arteries. The internal carotid artery enters the cranial cavity where it continue into the rostral cerebral artery which, together with caudal communicating artery and caudal cerebral arteries, from the circulus arteriosus. The vertebral areries

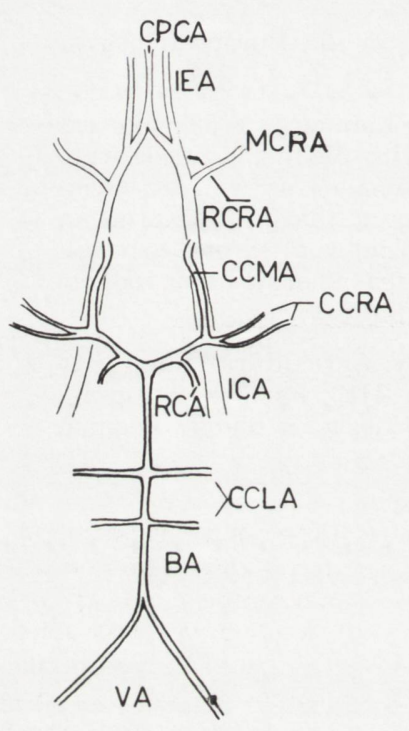

Fig. 1. The circulus arteriosus of Castor fiber (dorsal view). See Fig. 2 for explanations. fuse and form the basilar artery which supplies blood to the circulus arteriosus. Fig. 1 shows the circulus arteriosus of the European beaver.

The external carotid artery, by means of its branches, supplies the organs of the facial region of the head (Fig. 2). The first branch which arises from external carotid artery is the occopital artery. Then the lingual and facial arteries take origin. The lingual artery gives of the dorsal lingual rami and sublingual artery. The facial artery gives off the submental artery and, bending, passes to on the lateral surface of the mandible and divides into inferior and superior labial arteries. The external carotid artery terminates by dividing into superficial temporal and maxillary arteries. The superficial temporal artery gives off the caudal auricular artery and continues as the transverse facial artery.

The maxillary artery is the main vessel forming the terminal portion of the external carotif system. Its barnches form three characteristic groups: (1) caudal deep temporal artery, inferior alveolar artery, middle meningeal artery, and pterygoid ramus, (2) nasal deep temporal and external ophthalmic arteries, (3) greater palatine artery, buccal artery, musculoglandular branch, sphenopalatine artery, and malar artery.

In the investigated beavers variations and asymmetries in the course, division and connections of some arteries were found. In 7 beavers (in 4 bilaterally) the occipital artery originated from the interial carotid artery. In 6 specimens (homolaterally) the caudal deep temporal artery and in 3 beavers (homolaterally) the nasal and deep temporal arteries were absent. Fig. $2 \mathrm{~b}-\mathrm{d}$ presents the frequency of varations of the terminal division of the cephalic arterial system in beavers. 

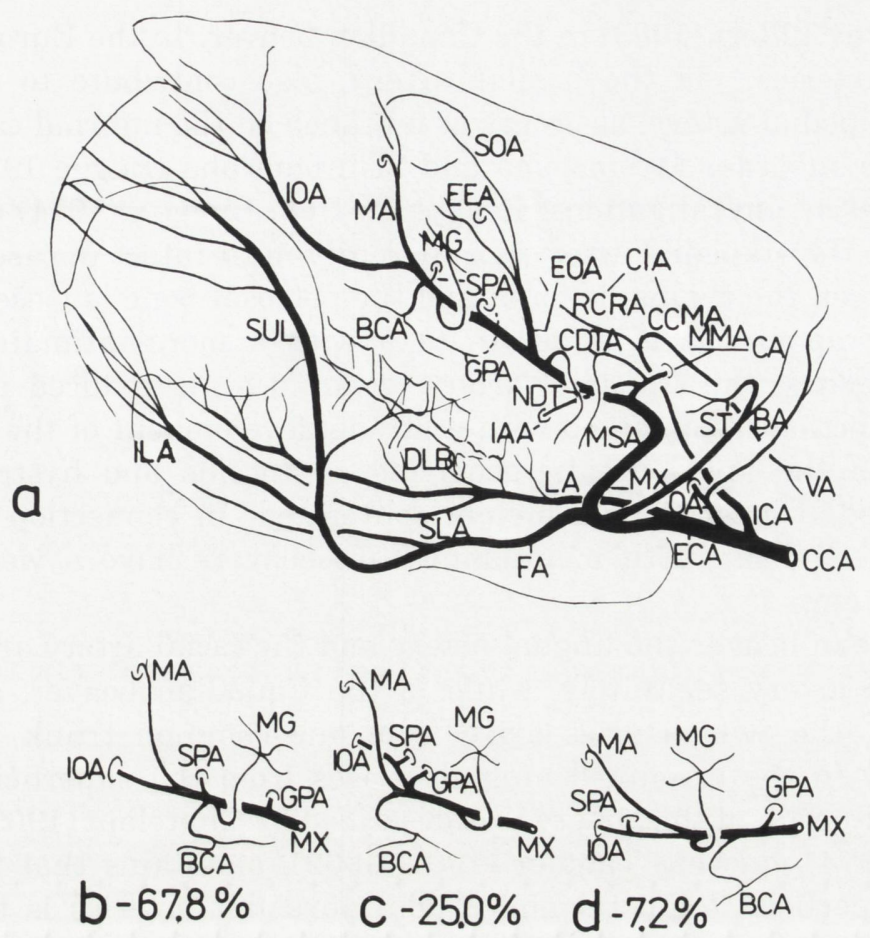

Fig. 2. Head arteries of Castor fiber (a) and variations of the maxillary artery final branching (b-d); lateral view. Explanation of abbreviations used in figures: BA - basilar artery, BCA - buccal artery, CA - caudal auricular artery, CCA - common carotid artery, CCLA - caudal cerebellar artery, CCMA - caudal communicating artery, CCRA - caudal cerebral arteries, CDTA - caudal deep temporal artery, CIA - circulus arteriosus, CPCA - corpus callosum artery, DLB - dorsal lingual branches, ECA - external carotid artery, EEA - external ethmoideal artery, EOA - extarnal ophthalmic artery, FA - facial artery, GPA - great palatine artery, IAA - inferior alveolar artery, ICA - internal carotid artery, IEA - internal ethmoidal artery, ILA - inferior labial artery, IOA - infraorbital artery, LA lingual artery, MA - malar artery, MCBA - middle cerebral artery, MG - musculoglandular branch, MMA - middle meningeal artery, MSA - masseteric artery, MX - maxillary artery, NDT - nasal deep temporal artery, OA - occopital artery, RCA - rostral cerebellar artery, RCRA - rostral cerebral artery, SLA - sublingual artery, SOA - supraorbital artery, SPA - sphenopalaine artery, ST superficial temporal artery, SUL - superior labial artery, VA - vertebral artery.

\section{Discussion}

The internal carotid artery, as a permement vessel in the European beaver, was described by Andreyeva (1954) and Bugge (1971, 1974), and in the Canadian beaver by Guthrie (1963). In contributes to the circulus arteriosus. However, in other rodents from the suborders of Sciuromorpha, Protrogomorpha, Caviomorpha, and Hystricomorpha, the internal carotid artery is lacking (Bugge 1974). The branches forming the circulus arteriosus in the European beaver are similar to 
those described by Pilleri (1983) in the Canadian beaver. In the European beaver the vertebral arteries, via the basilar artery, also contribute to the circulus arteriosus. A stapedial artery, as occurs as a branch od the internal carotid artery in species of the suborder Myomorpha and Sciuromorpha (Bugge 1974), was not found in the present investigations. It appears from Bugge's (1971) observations that, in rodents, the stapedial artery is apparently most intact in cases where the connection between the tympanic bulla and the petrosal bone is loose, and where the masticatory apparatus is weak. In taxa with a more intimate connection between these bones, the stapedial artery (sciuroides), is reduced in particular where this connection is combined with a strong development of the masticatory apparatus, as in the aplodontoids, geomyids, castoroids and hystricomorphus, where the stapedial artery is completely obliterated. In connection with theses interdependencies, it is worth mentioning that beavers have a well developed masticatory system.

In the European beaver the lingual artery and the facial artery arise from the external carotid artery separately, while in the Canadian beaver, according to Guthrie (1963), the two arteries arise from one common trunk. The caudal auricular artery in the examined animals arises from the superficial temporal artery. A similar origin of this artery was described by Chatelain (1969) in rabbits. Bugge (1971, 1974), quoting Tandler (1901, 1902), maintains that the common trunk of the superficial temporal and caudal auricular arteries is the terminal branch of the external carotid artery. In descriptions of cephalic arteries in rodents, Bugge $(1971,1974)$ does not distinguish the maxillary artery, and sign the vessel as a distal part of the stapedial artery. Nomina Anatomica Veterinaria (1983) and Simoens et al. (1978-1979) suggested that the external carotid artery, in its terminal portion, bifurcates into the superficial temporal and the maxillary arteries. In the opinion of Guthrie (1963), the maxillary artery in Castorimorpha arises from the proximal part of the external carotid artery. Michael and Rothkegel (1960) found the maxillary artery in hamsters. Finally, Wible (1987) states that "in all recent mammals except some insectivorans and rodents, an anastomosis forms between the distal portions of the external carotid system and ramus inferior near the exit of mandibular nerve from the cranial cavity. These anastomotic links, all of which are generally called maxillary arteries, exhibit a remarkable degree of variability in their origins, courses, and relationships to other structures". This author distinguishes under the category "maxillary artery" five sorts of vessels. The artery in some rodents would subsume them under number 1 and 5 his categories. However, in his table 2 (Character Analysis of the Eutherin Stapedial Artery) Wible (1987) leads one to belive that Rodentia lack the maxillary artery. Terminology concerning cephalic arteries of rodents suggested by Bugge (1971, 1974) and Wible (1987) can be accepted in studies of ontogenesis of these vessels. However, Wible (1987) maintains that ontogeny of the stapedial artery has been studied in detail in only thirteen forms representing nine of the twenty modern orders and it should be stressed that these studies did not include beavers. In the 
present study, in agreemnet with Nomina Anatomica Veterinaria (1983) and in agreement with suggestions of Simoens et al. (1978-1979) the term "maxillary artery" denotes the vessel which forms a continuation of the cephalic arterial system beginning from the origin of the superficial temporal artery from the external carotid artery. The examined beavers showed variations and asymmetry of course and distribution of some arteries. The variability of arteries occurs also in other animal species and in humans, and it is the result of the so called "plasticity" of blood vessels which in the prenatal period show predispositions of different vessel varieties. On the the other hand, it was found that in all exemined animals the internal carotid artery is a branch of the common carotid artery and the stapedial artery is obliterated. It seems that this pattern characteristic for the cephalic arterial vescularization may by helpful in the taxonomy of Castorimorpha. Bugge (1971) observed that the stapedial artery is absent in the castorids but is quite well developed in sciuroids, while the internal carotid artery is well developed in castoroids but is absent in sciuriods, distal to the departure of the stapedial artery. Results of these investigations are in agreement with Bugge's (1974) opinion that, based on the cephalic arterial vascularization pattern, there is a clear taxonomic distinction between Castorimorpha and Sciuromorpha.

Acknowledgments: We are greatly indebted to Prof S. Godynicki, Head of the Department of Anatomy of Animals, Agricultural University of Poznań, for his critical remarks on the manuscript and we would also like to thank Prof W. Woźniak, Head of the Chair and Department of Human Anatomy, Medical Academy of Poznań, for his help in preparing the English version of this paper.

\section{References}

Andreyeva E. G. 1954. [The vasculatory system in the European beaver]. Trudy Voronezhskogo Gasudarstvennogo Zapovednika 5: 30-50. [In Russian]

Bugge J. 1971. The cephalic arterial system in sciuromorphs with special reference to the systematic classification of rodents. Acta Anatomica 80: 336-361.

Bugge J. 1974. The cephalic arterial system in insectivores, primates, rodents and lagomorphs. Acta Anatomica 87, suppl. 62: 1-160.

Chatelain E. 1969. Contribution a' l'etude de la vascularisation arterielle de la tete du lapin (Oryctolagus cuniculus L.). These pour le Doctorat Veterinaire, Ecole Nationale Veterinaire, Alfort: 1-75.

Guthrie D. A. 1963. The carotid circulation in the Rodentia. Bulletin of the Museum of Comparative Zoology of the Harvard University 128: 455-481.

Michael G. and Rothkegel R. 1960. Die Aufzweigung der A. carotis communis beim Syr. Goldhamster (Mesocricetus auratus W.). Anatomische Anzeiger 108: 272-284.

Munkacsi S. 1957. Über die Verwendung der Kunststoffe Polyvinylchlorid (PVC) und Piacryl in der Korrosionstechnik. Zeitschrift für wisenchaftiche Mikroskopie und mikroskopische Technik 63: $352-356$.

Nomina Anatomica Veterinaria. 1983. Third ed. Published by the International Committee on Veterinary Gross Anatomical Nomenclature. Ithaca, New York: 1-209.

Pilleri G. 1983. Central nervous system, craniocerebral topography and cerebral hierarchy of the Canadian beaver (Castor canadensis). [In: Investigations on beavers. G. Pilleri, ed]. Institute of Brain Anatomy, University of Berne, vol. 1: 19-59. 
Simoens P., De Vos N. R. and Lauwers H. 1978-1979. Illustrated anatomical nomenclature of the heart and the arteries of head and neck in the domestic mammals. Mededelingen van de Faculteit. Diergeneeskunde Rijksuniversiteit Gent 21: 1-100.

Tandler J. 1901. Zur vergleichenden Anatomie der Kopfarterien bei den Mammalia. Anatomische Hefte 18: 327-368.

Tandler J. 1902. Zur Entwicklunsgeschichte der Koparterien bei den Mammalia. Morphologisches Jahrbuch 30: 275-373.

Wible J. R. 1987. The eutherian stapedial artery: character nalysis and implications for superordinal relantionships. Zoological Journal of the Linnean Society 91: 107-135.

Received 14 January 1997, accepted 21 August 1997. 